\title{
Conserving populations at low abundance: delayed functional maturity and Allee effects in reproductive behaviour of the queen conch Strombus gigas
}

\author{
Joanna Gascoigne ${ }^{1,2, *}$, Romuald N. Lipcius ${ }^{1}$ \\ ${ }^{1}$ Virginia Institute of Marine Science, The College of William and Mary, Gloucester Point, Virginia 23062, USA \\ ${ }^{2}$ Present address: School of Ocean Sciences, University of Wales Bangor, Askew Street, Menai Bridge, Anglesey LL59 5AB, UK
}

\begin{abstract}
Effectiveness of conservation measures for diminished populations depends on the mechanism producing low abundance. In queen conch, which is heavily exploited, reproductive activity is depressed where conch density is low, which may be due to the Allee effect, poor habitat quality, or delayed functional maturity. To determine the mechanism underlying impaired reproduction in shallow seagrass beds, mature conch were translocated from 'source' sites with high and low ambient conch density ( 1000 and $\sim 20$ conch $\mathrm{ha}^{-1}$, respectively), and kept at high density in enclosures within high- and low-density 'host' sites. We monitored reproductive activity, and modelled conch population dynamics under exploitation, a reproductive Allee effect, and delayed functional maturity. In the field, conch from high-density source sites had significantly higher reproductive activity than those from low-density sites, although conch density was the same in all treatments. Thus, reduced reproductive activity at low conch density in shallow seagrass habitats is not due strictly to an Allee effect. Physiological condition of conch did not differ between treatments, regardless of habitat quality. Conch from high-density source sites had thicker shell lips, indicating that they were older, and they displayed significantly higher reproductive activity than younger conch with thinner lips. The field, morphological, and physiological evidence is therefore consistent only with a mechanism of delayed functional maturity. In model simulations, either an Allee effect or delayed functional maturity, combined with exploitation, produced non-linear population collapses. Young adult queen conch that are not functionally mature occur at low density in shallow seagrass habitats, and are heavily exploited before reproducing. Conservation efforts must be directed at these habitats, and not only to habitats where older functionally mature adults are at high density and not susceptible to Allee effects.
\end{abstract}

KEY WORDS: Allee effect · Positive density dependence $\cdot$ Inverse density dependence $\cdot$ Depensation · Functional maturity $\cdot$ Queen conch

Resale or republication not permitted without written consent of the publisher

\section{INTRODUCTION}

In most equilibrium population models, individual fitness is inversely related to population density (Gotelli 1998). However, in some cases organisms benefit from the presence of conspecifics at low density (see review by Fowler \& Baker 1991); e.g. encounters with potential mates (Kuussaari et al. 1998), fertilisation efficiency in broadcast spawners (Levitan et al. 1992, Baker \& Tyler 2001), plant pollination success (Widen 1993, Groom 1998, Hackney \& McGraw 2001), vigilance against predators (Kenward 1978) and social structure (Shepherd \& Brown 1993, Courchamp et al. 2000). In these instances, fitness declines as population density decreases such that per capita population growth rate may become negative and local extinction may result (Courchamp et al. 1999). Population dynamics of this kind are known as Allee effects (Allee 1931). Allee effects do not necessarily cause extinction since per capita population growth rate can be depressed but still remain positive.

Stoner \& Ray-Culp (2000) provide field evidence for a reproductively driven Allee effect in the queen conch Strombus gigas, a large, heavily exploited, tropical 


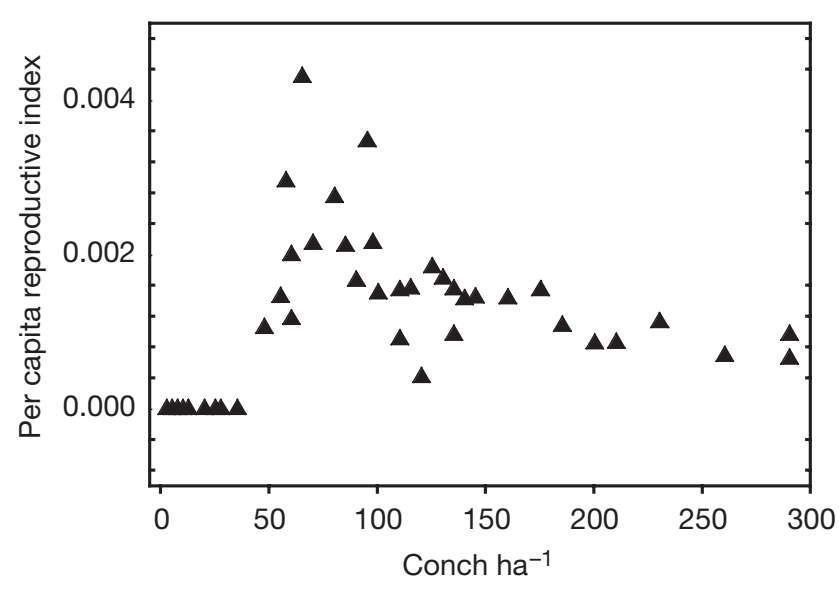

Fig. 1. Strombus gigas. Relationship between per capita reproductive activity and adult queen conch density in the Exuma Cays, Bahamas (adapted from Stoner \& Ray-Culp 2000)

gastropod. In surveys of a conch population in Exuma Sound, Bahamas, no reproductive activity was observed where adult conch density was less than $50 \mathrm{ha}^{-1}$ (Fig. 1). The presumed mechanism was a reduced encounter rate with suitable mates at low conch densities due to low mobility. Copulation in conch is also more likely in spawning than non-spawning females, providing another positive feedback mechanism that would enhance this effect (Appeldoorn 1988a).

If the reduced reproductive activity were due to an Allee effect, then conservation efforts might be directed at either protecting conch where they are at high density, or augmenting conch densities where they are at low.

If however, decreased reproductive activity where conch density is low were due to other mechanisms, then conservation efforts might have to be quite different from those used where an Allee effect exists. For example, conch in nearshore habitats of the Florida Keys are not reproductively active, whereas those in offshore habitats reproduce (McCarthy et al. 2002). This is apparently due to the poor quality of nearshore habitats (Glazer \& Quintero 1998), as conch translocated from nearshore to offshore habitats initiated reproduction (Delgado et al. 2004). In this case, an appropriate conservation approach would be to protect conch in offshore habitats, and possibly augment these with conch translocated from nearshore habitats (Delgado et al. 2004). Moreover, there are alternative mechanisms that might underlie diminished reproductive activity where conch density is low besides the Allee effect and habitat quality, such as an environmental cue for reproduction, seasonal migrations, or delayed functional maturity (see Table 1). Adult conch migrate seasonally between feeding and reproductive sites, at least in deep water (Stoner \& Sandt
1992, Stoner et al. 1992). Hence, conch might migrate between high-density spawning grounds, where environmental cues for reproduction (e.g. for larval transport) are present, and low-density feeding areas, where reproductive activity is minimal. Another mechanism involves delayed functional maturity, which is common in various phyla (e.g. crabs and lobsters; see Lipcius 1985), and which might characterize molluscs that exhibit secondary sexual characters, such as the queen conch. Specifically, queen conch cease growth in shell length upon attaining sexual maturity, and instead divert their energy to thickening of the shell lip, which dramatically reduces the likelihood of predation. It has been assumed that conch with shell lips thicker than a few millimetres are mature; they and their older conspecifics are heavily exploited and in decline throughout most of the species range (Berg \& Olsen 1989, Anon 1999). During maturation, conch progressively migrate from shallower nursery grounds to deeper adult habitats (Randall 1964, J. Gascoigne pers. obs.). Conch mature a few months after developing a flared lip on the shell (Appeldoorn 1988b), when the shell is at least $5 \mathrm{~mm}$ thick (Egan 1985). However, newly morphologically mature conch may become functionally mature gradually, and these newly mature conch might be at low population density compared to their more reproductively active counterparts due to ontogenetic migration, low adult mortality and the associated accumulation of conch in adult habitats. If delayed functional maturity characterizes the queen conch, then exploitation of functionally immature adults might have dire population consequences. Thus, in field experiments we assessed the hypothesis that delayed functional maturity occurs in queen conch, and with matrix projection models we determined the potential population consequences of exploitation upon functionally immature conch.

More generally, this is of interest because the other mechanisms are not strictly Allee effects. Although they predict a correlation between low density and low per capita reproductive output, the decline in fitness is not caused by low density, but by other factors (e.g. habitat quality, reproductive status) which are correlated with both density and reproductive output. This is important in trying to predict the population consequences of the ongoing 'experiment' in fishing conch to low density throughout much of their range (Berg \& Olsen 1989, Anonymous 1999). Conservation strategies devised for Allee effects and disregarding other explanations may be ineffective and lead to population collapse.

We designed a manipulative field experiment to test whether an Allee effect due to low encounter rate was the sole mechanism for the lack of queen conch reproduction at low population density, and if not, to dis- 
Table 1. Strombus gigas. Expected level of reproductive activity from each translocation given alternative mechanisms associated with low population density. All conch were at high density in enclosures. There were 4 treatments: (1) control: conch from highdensity source sites put back into enclosures at the same site (high-high), (2) conch from high-density source sites translocated to enclosures in low-density host sites (high-low), (3) conch from low-density source sites translocated to high-density host sites (low-high) and (4) control (low-low)

\begin{tabular}{|c|c|c|c|c|c|c|}
\hline & \multirow[t]{2}{*}{$\begin{array}{l}\text { Allee } \\
\text { effect? }\end{array}$} & \multirow[t]{2}{*}{ Mechanism } & \multicolumn{4}{|c|}{$\begin{array}{c}\text { Translocation } \\
\text { (Source site density - Host site density) }\end{array}$} \\
\hline & & & High-high & High-low & Low-high & Low-low \\
\hline $\mathrm{H}_{0}$ & Yes & Encounter rate & High & High & High & High \\
\hline $\mathrm{H}_{\mathrm{A} 1}$ & No & Environmental trigger for reproduction & High & Low & High & Low \\
\hline $\mathrm{H}_{\mathrm{A} 2}$ & No & Seasonal reproductive migration into spawning sites & High & High & Low & Low \\
\hline $\mathrm{H}_{\mathrm{A} 3}$ & No & $\begin{array}{l}\text { Functionally mature conch in high density areas; } \\
\text { immature in low density areas }\end{array}$ & High & High & Low & Low \\
\hline $\mathrm{H}_{\mathrm{A} 4}$ & No & Poor condition in low density areas & High & High & Low & Low \\
\hline
\end{tabular}

tinguish between competing mechanisms (Table 1). First, we selected sites of high ( $\gg 50$ ind. ha ${ }^{-1}$ ) and low $\left(<50\right.$ ind. $\left.\mathrm{ha}^{-1}\right)$ adult conch density to meet the density criteria for an Allee effect (Stoner \& Ray-Culp 2000). We then transplanted mature conch between sites of high and low population density, with controls, placing the conch in enclosures at high density. The conch were deemed to be mature when they had a shell lip thicker than $5 \mathrm{~mm}$ (Egan 1985). The use of high-density enclosures, along with other corroborating data (see below) permitted us to distinguish between several alternative hypotheses (Table 1).

If an observed pattern of low reproductive activity in conch were indeed due purely to an Allee effect mediated by reduced encounter rates with potential mates, we would expect equally high reproductive activity in all enclosures, regardless of treatment, since conch inside all the enclosures would be at high density. This was, therefore, our null hypothesis (Table 1: $\mathrm{H}_{0}$ ). An effect of host-site density (high reproductive activity in conch transplanted to high-density sites) would imply that these sites have an environmental trigger for reproduction that attracts reproductive conch, and which the low-density sites lack (Table 1: $\mathrm{H}_{\mathrm{A} 1}$ ). An effect of source-site density (high reproductive activity in conch transplanted from high-density sites) would be explained by a site-mediated factor that controls both reproductive activity and density, such as sitespecific differences in conch age, growth, condition (habitat quality), or reproductive status (e.g. if conch migrate between reproductive [high-density] and feeding [low-density] sites; Table 1: $\mathrm{H}_{\mathrm{A} 2-4}$ ).

To distinguish site-specific differences that might control conch density and reproduction, as well as to ensure that all conch used in the experiment were reproductively competent, we assessed shell morphology, conch condition and reproductive status at each site (Stoner \& Sandt 1992, Stoner \& Schwarte 1994). If conch were migrating freely between sites (Table 1:
$\mathrm{H}_{\mathrm{A} 2}$ ), we expected no significant morphological differences between sites. If there were site-specific reproductive output controlled by differences in habitat quality (Table 1: $\mathrm{H}_{\mathrm{A} 4}$ ), we would expect differences in conch condition index, and in the allocation of resources to reproductive and somatic tissue.

Finally, we developed a stage-based matrix population model (Caswell 2001) for queen conch to estimate the population-level consequences of Allee and non-Allee mechanisms underlying the patterns in reproductive activity.

\section{MATERIALS AND METHODS}

Site characteristics and surveys. We conducted the experiments at 4 sites near Lee Stocking Island, Exuma Cays, Bahamas (Fig. 2). Two sites had high densities of mature conch (Rainbow Gardens: 1140 ind. ha ${ }^{-1}$, Bock Cay: 963 ind. $\mathrm{ha}^{-1}$ ) and 2 sites had low densities (Children's Bay Cay (CBC): 19.1 ind. ha ${ }^{-1}$, Shark Rock: 21.2 ind. ha ${ }^{-1}$ ). Low density was defined as $<50$ mature ind. $\mathrm{ha}^{-1}$, the proposed lower limit for reproductive activity (Fig. 1; Stoner \& Ray-Culp 2000). Shark Rock had a total conch density of 127 ind. ha ${ }^{-1}$, but most were immature; the other 3 sites only had mature conch. We measured conch density in $25 \mathrm{~m} \times 1 \mathrm{~m}$ transects (Rainbow) or circles of radius $10 \mathrm{~m}$, covering a total area of not less than $1000 \mathrm{~m}^{2}$. The habitat at all 4 sites was moderately dense seagrass with strong tidal currents. Shark Rock and CBC ranged in depth from 2 to $4 \mathrm{~m}$, Rainbow 3.5 to $4 \mathrm{~m}$ and Bock 7 to $9 \mathrm{~m}$. We surveyed the low-density sites extensively while searching for mature conch and observed no evidence of reproductive activity (e.g. mating, egg masses). Mating was very commonly observed at the high-density sites, but only quantified at Bock Cay, where 11 out of 121 animals (9.1\%) were engaged in reproductive activity during the survey. Levels of reproductive activity at Rainbow were similar. 


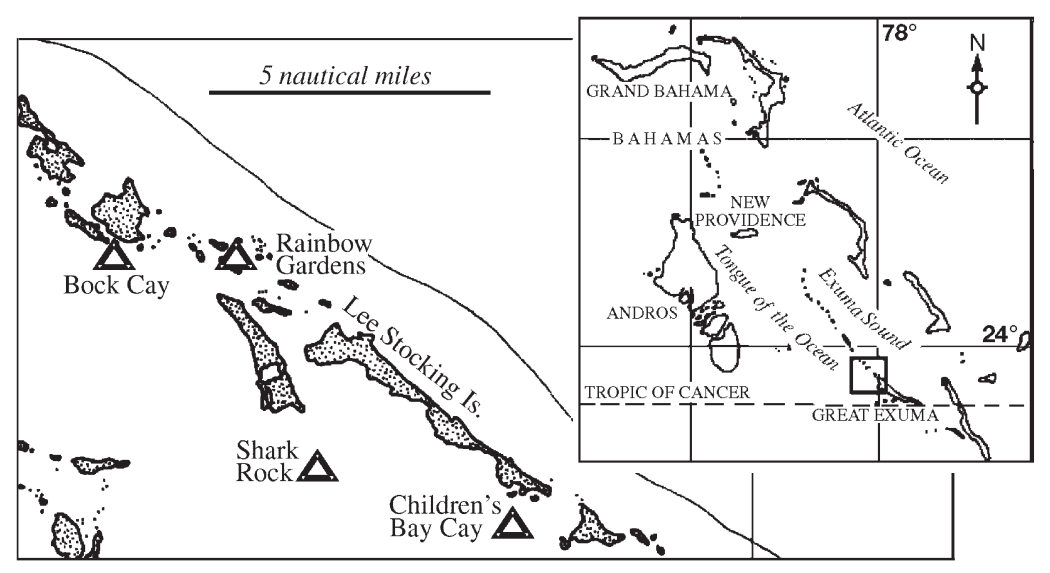

Fig. 2. Sites in the Exuma Cays, Bahamas

Experimental design. We collected 64 conch haphazardly from each site and randomly allocated them to 1 of 4 groups: 2 control treatments and 2 translocation treatments. Conch were tagged and placed in an enclosure either back at the same site (control) or translocated to a paired site (Rainbow-CBC, BockShark). Each enclosure ( $6 \mathrm{~m}$ diameter, $28.3 \mathrm{~m}^{2}$ area) contained 16 conch, yielding a foraging area of $1.8 \mathrm{~m}^{2}$ per conch and a high density that should trigger reproductive behaviour, but one that is well within the upper range of densities observed in older juveniles and young adults (Stoner et al. 1988, Stoner \& Ray 1993). Enclosures were made of 20 to $25 \mathrm{~cm}$ Vexar strips supported by PVC and retained most of the conch while not visibly altering the habitat. We conducted the experiment twice, once from 22 to 31 July 2001 (Expt 1) and again from 2 to 14 August 2001 (Expt 2). Procedures were similar in both experiments.

While the experiment was running, we checked enclosures daily or twice daily, using either snorkel or SCUBA, and recorded the tag numbers of conch involved in reproductive activity (Stoner \& Ray-Culp 2000), which included (1) copulation (a pair of conch lined up with the front of the male shell covering the back of the female shell, male extending the penis into the female mantle cavity) and (2) pairing (a pair of conch lined up as for copulation but without the male penis extended). We also recorded the number of conch in each cage so that results would not be biased by escape from the enclosures, although the escape rate was low (an average of $\sim 2$ from each cage during each experiment).

We checked enclosures at the Rainbow-CBC site pair 14 times during Expt 1 and 17 times during Expt 2, and at the Bock-Shark site pair 7 times during Expt 1 and 9 times during Expt 2. We calculated a reproductive index (number of matings [pairing or copulation] per observation per conch) for each enclosure so that results could be compared across all enclosures, sites and experiments.

Morphological data. At the end of Expt 2, we haphazardly collected 4 conch from each enclosure (i.e. $\mathrm{n}=16$ for each site), determined their gender and measured their shell features (length, weight and lip thickness). We assessed their condition using the ratios of flesh wet weight: shell length (Stoner \& Sandt 1991, Ray \& Stoner 1995) and flesh wet weight:shell weight. We froze and subsequently dissected and weighed gonad samples to estimate allocation of resources to reproductive versus somatic tissue (ratio of gonad wet weight to flesh wet weight). We used gonad colour as an indicator of reproductive status in males (orange $=$ producing sperm; Reed 1995).

Data analysis. Reproductive activity: Reproductive index $(R I)$ was calculated as follows:

$R I=$ observed copulations and pairings

mean no. conch in enclosure $\times$ no. observations on enclosure

In an ANOVA model, RI was the dependent variable, and source site and host site were fixed factors. To account for the effect of location (= system) and experimental period, we included system and time as fixed factors with 2 levels corresponding to the 2 pairs of sites (system 1 = Rainbow / Children's Bay Cay; system 2 = Bock Cay/Shark Rock) and the 2 experimental periods.

Since mating activity was recorded by conch tag number, we also had a record of individual matings. We were, therefore, able to determine if the pattern of matings was driven by a few active individuals and if there was evidence for mate choice. For each of the 32 enclosures ( 4 replicates $\times 4$ sites $\times 2$ expts), we compared these to a Poisson distribution, using a $\chi^{2}$ test, to assess whether the distribution of mating activity among individuals was random, uniform or clumped. A clumped distribution would mean that a few individuals were responsible for most of the reproductive activity. In 8 cases, $\chi^{2}$ could not be calculated because there were too few matings in the enclosure.

To test whether there were significant changes in reproductive activity over the course of the experiment, we divided each experiment into 2 periods of 1 wk each. We tested the distribution of mating against a Poisson distribution to check if it was random and then compared the mean rate of matings in the 2 time periods using a $\chi^{2}$ test (Zar 1999). In this case, we had 
to combine replicate enclosures and experiments to have an adequate sample size, and even then only 4 of 8 site pairs could be analysed.

Sex ratio: We compared the sex ratio of the subsample from each site using a binomial distribution with $\mathrm{p}=$ 0.5, which would be expected for a random sample of a 1:1 sex ratio. We also compared individual sites and high versus low density sites using $\chi^{2}$ tests $(\alpha=0.05)$.

Morphological data: We analysed morphological measurements (shell length and weight, lip thickness, flesh weight:shell weight ratio, and gonad weight: flesh weight ratio) using an analysis of variance model with source density, system and sex as fixed factors. We used Student-Newman-Keuls (SNK) pairwise comparisons to compare levels of a factor within each level of another factor when there were interaction effects (Underwood 1997).

Modelling. We used a population matrix projection model (Caswell 2001) with density-dependent reproduction to compare population trajectories with and without Allee effects, and with delayed functional maturity. The model has a juvenile stage and a series of adult stages (Fig. 3, Table 2). Individuals move through the stages at each time step (=1 yr), spending a fixed number of years as a juvenile (J1: Fig. 3, $T_{\mathrm{i}}$ : Table 2) and $1 \mathrm{yr}$ each in adult stages 1 and 2 . Individuals accumulate in adult stage 3, dying at a rate determined by adult mortality and exploitation of adult stage 3 (Table 2). Hence, the model is appropriate for long-lived iteroparous species. Reproduction is negatively density dependent across all densities except in the Allee model, where it is positively density dependent at low density, with the strength of positive density dependence being fixed by the Allee factor $\delta$ (Myers et al. 1995, Stoner \& Ray-Culp 2000).

We ran the model in 4 ways (Table 2):

(1) Model 'Null1': All adult stages reproduce $(D=1)$, all adult stages are fished $\left(F_{1}=F_{2}\right)$, and there are no Allee effects $(\delta=1)$.

(2) Model 'Null2': Only adults in stage 3 reproduce $(D=0)$, only adults in stage 3 are fished $\left(F_{1}=0\right)$, no Allee effects $(\delta=1)$.

(3) Model 'Rep': Only adults in stage 3 reproduce, but all adults are fished, no Allee effects $(\delta=1)$.

(4) Model 'Allee': All adults reproduce and are fished (as in Null1), but reproduction is subject to different strengths of Allee effect ( $\delta=1$, no Allee effect; $\delta=3$, intermediate Allee effect; $\delta=5$, strong Allee effect).

The parameter $\delta$ is an index of the Allee effect (Myers et al. 1995). For the 3 models with simple negative density-dependent reproduction (Null1, Null2 and Rep), $\delta=1$, hence the re-

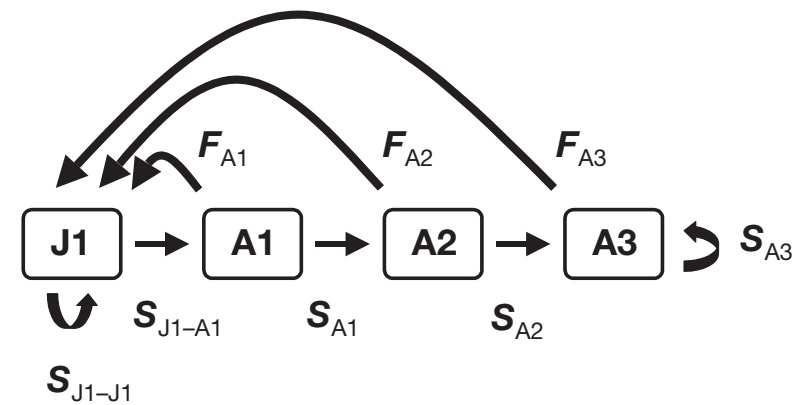

Fig. 3. Strombus gigas. Life-cycle diagram for the queen conch population matrix projection model. The life cycle is composed of a juvenile stage (J1) and 3 adult stages (A1 to A3). The transition probabilities (S) reflect growth and survival to the next stage (Table 3 ), including retention of some fraction of juveniles in the juvenile stage $\left(S_{\mathrm{J} 1-\mathrm{J} 1}\right)$ and adults in the last adult stage (A3). Reproductive contributions of each adult stage are indicated as $F_{1}$ to $F_{3}$

production equation collapses to $\alpha / 1+\beta N_{\mathrm{A} t}$, where reproductive output tends to a maximum of $\alpha$ as $N_{\mathrm{A}}$ declines to 0 , and tends to 0 as $N_{\mathrm{A}}$ increases. Parameter $\beta$ sets the slope of the curve, and in this heuristic model $\beta$ was set such that the slope was over appropriate values of $N_{\mathrm{A}}$, so that the model equilibrated at reasonable population values $(\alpha=1000 ; \beta=0.01)$. Increasing $\delta$ gives a curve that looks similar at high values of $N_{\mathrm{A}}$ but causes it to drop back to 0 as $N_{\mathrm{A}}$ tends to 0 , as would an Allee effect (Myers et al. 1995).

Unlike the other models, the Allee model took $N_{\mathrm{A}}$ in values of density rather than population size, necessitating a change in parameterisation $(\beta=45)$. In the Allee model, all adult stages reproduce and $F_{1}=F_{2}$, as

Table 2. Strombus gigas. Generalised transition matrix for population model. $T_{\mathrm{i}}=$ time to physiological maturity (time spent as juvenile), $M_{\mathrm{i}}=$ juvenile mortality, $M_{\mathrm{a}}=$ adult mortality, $F_{1}=$ mortality due to exploitation in adult stages 1 and $2, F_{2}=$ mortality due to exploitation in adult stage 3 , $N_{\mathrm{A} t}=$ total number of adults at time $t$ and $\alpha, \beta$ and $\delta$ are parameters for the density dependent equation. The parameter $D$ fixes delayed reproduction ( $D=0$, adult stages 1 and 2 do not reproduce) versus immediate reproduction ( $D=1$, all adult stages reproduce). Values of $T_{\mathrm{i}}, M_{\mathrm{i}}$ and $M_{\mathrm{a}}$ were fixed to be approximately appropriate for queen conch, although since the model is heuristic and comparative, and values were equal across all models, they do not affect the results. In the case presented here, $T_{\mathrm{i}}=3, M_{\mathrm{i}}=2$ and $M_{\mathrm{a}}=0.5$

\begin{tabular}{|ccccc|}
\hline & Juvenile & Adult 1 & Adult 2 & Adult 3 \\
\hline Juvenile & $\left(1-\frac{1}{T_{\mathrm{i}}}\right) \cdot \mathrm{e}^{-M_{\mathrm{i}}}$ & $\frac{D \cdot \alpha N_{\mathrm{A} t}^{(\delta-1)}}{1+\beta N_{\mathrm{At}}^{\delta}}$ & $\frac{D \cdot \alpha N_{\mathrm{At}}^{(\delta-1)}}{1+\beta N_{\mathrm{A} t}^{\delta}}$ & $\frac{\alpha N_{\mathrm{At}}^{(\delta-1)}}{1+\beta N_{\mathrm{A} t}^{\delta}}$ \\
Adult 1 & $\frac{1}{T_{\mathrm{i}}} \cdot \mathrm{e}^{-\frac{1}{2}\left(M_{\mathrm{i}}+M_{\mathrm{a}}+F_{1}\right)}$ & 0 & 0 & 0 \\
Adult 2 & 0 & $\mathrm{e}^{-\left(M_{\mathrm{a}}+F_{1}\right)}$ & 0 & 0 \\
Adult 3 & 0 & 0 & $\mathrm{e}^{-1 / 2\left(2 M_{\mathrm{a}}+F_{1}+F_{2}\right)}$ & $\mathrm{e}^{-\left(M_{\mathrm{a}}+F_{2}\right)}$ \\
\hline
\end{tabular}


in Model Null1. Because of the differences in model structure and parameters, it is not directly comparable to the straightforward negative density-dependent models. We, therefore, examined the influence of Allee effects by comparing $\delta=3$ (intermediate Allee effect) and $\delta=5$ (strong Allee effect) (Stoner \& Ray-Culp 2000 ) with $\delta=1$ (null model of no Allee effect).

The models were run for 200 time steps, by which time they had all reached an equilibrium population size for each stage. They were run over a range of $F$ values and the equilibrium adult population size plotted against $F$. The initial population size did not affect the equilibrium population size for Models Null1, Null2 and Rep. All runs were started with 1000 individuals in each stage $\left(N_{\mathrm{A}}=3000\right)$. In the case of the Allee model, the area of each stage was set at 1000 units and the density of each stage at 1 (giving the same initial population size). The initial density affected the equilibrium population size, but did not alter the dynamics significantly (i.e. the value of $F$ at which the models reached extinction).

\section{RESULTS}

In all analyses of variance, variances were either not significantly heterogeneous (Levene's test), or the null hypothesis for the $F$-test was rejected at an $\alpha$ value lower than that used to test for homogeneity of variance (Underwood 1997). Hence, transformations were not required.

\section{Mating behaviour and reproductive index}

In the analysis of mating behaviour (Table 3) the interaction effect between source site density and

Table 3. Strombus gigas. Incidents of mating (copulation and pairing) in each treatment for the 2 experiments. Note that for logistical reasons the CBC-Rainbow system was checked more frequently during each experiment so that higher numbers of observed matings in that system reflect this. We calculated the reproductive index as an estimate of reproductive activity which is unbiased by numbers of checks as well as by the few escapes

\begin{tabular}{|llcc|}
\hline Source site & Host site & $\begin{array}{c}\text { Matings } \\
\text { Expt 1 }\end{array}$ & $\begin{array}{c}\text { Matings } \\
\text { Expt 2 }\end{array}$ \\
\hline CBC & CBC & 3 & 0 \\
CBC & Rainbow & 2 & 6 \\
Rainbow & Rainbow & 16 & 25 \\
Rainbow & CBC & 4 & 2 \\
Shark Rock & Shark Rock & 3 & 2 \\
Shark Rock & Bock Cay & 2 & 0 \\
Bock Cay & Bock Cay & 7 & 8 \\
Bock Cay & Shark Rock & 3 & 11 \\
\hline
\end{tabular}

host site density was significant (ANOVA, $p=0.017$ ), precluding singular conclusions about the main effects. When analysed within treatment combinations (SNK tests, $\alpha=0.05)$, the reproductive index $(R I)$ was higher for conch from high-density source sites than for conch from low-density source sites, irrespective of host site (Fig. 4). In addition, the $R I$ for conch from high-density source sites returned to high-density host sites was higher than the $R I$ for conch translocated to lowdensity host sites. The $R I$ values of conch translocated from low-density source sites did not differ, irrespective of host-site density.

There was also a significant system $\times$ host site density interaction effect (ANOVA, $p=0.042$ ), because the effect of host site density was only significant (SNK tests, $\alpha=0.05$ ) in 1 of the systems (Rainbow/Children's Bay Cay). Hence, the strongest effect upon the RI was that of source site density, such that all enclosures with conch from source sites with high conch densities had high values of the $R I$, and all those with conch from source sites with low conch densities had lower values of the RI (Fig. 4).

Out of the 24 enclosures for which $\chi^{2}$ could be calculated, only 3 had a distribution of mating activity between individuals that differed significantly from random and these 3 were more uniform than random (i.e. more individuals participating in fewer matings). The results were, therefore, not due to a few active individuals and there was little evidence for mate choice or any other mechanism that would create a non-random distribution of matings.

When replicates and experiments were combined, none of the source site $\times$ host site combinations had a distribution of individual matings different from ran-

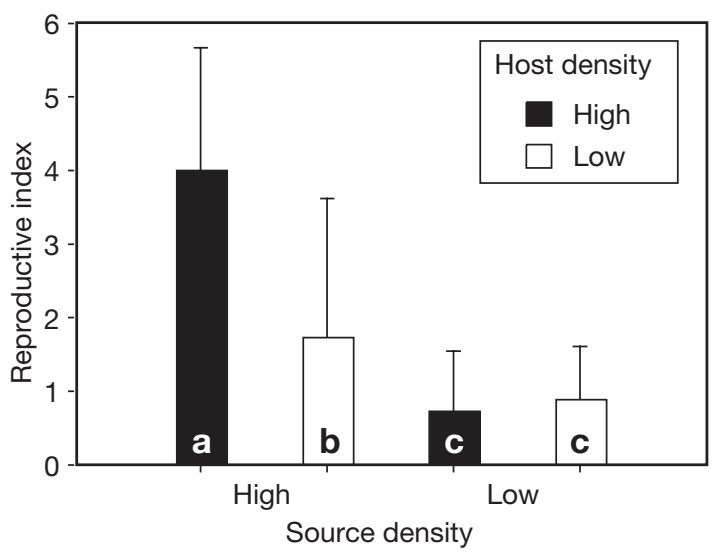

Fig. 4. Strombus gigas. Mean reproductive indices (+SD) for each combination of source site density and host site density. Treatment combinations that did not differ significantly (Student-Newman-Keuls pairwise comparisons) share the same letter 
dom $\left(\chi^{2}\right.$ test, $\left.\alpha=0.05\right)$. When the data were divided into $2 \mathrm{wk}$ periods, there were no significant differences in the rate of mating activity between the first and second halves of the experiments for the 4 site pairs that could be tested ( $\chi^{2}$ test, $\alpha=0.05$ ).

\section{Sex ratio}

Conch from one high-density source site (Bock Cay) had a significantly male-biased sex ratio $\left(\chi^{2}\right.$ test, $\mathrm{p}=$ 0.038). The other high-density site (Rainbow) had a slight but non-significant male bias. Overall, the conch from high-density source sites had a male-biased sex ratio $\left(\chi^{2}\right.$ test, $\left.p=0.021\right)$, whereas conch from lowdensity sites did not $\left(\chi^{2}\right.$ test, $\left.\mathrm{p}=0.298\right)$. Sex ratios of conch from high- and low-density sites differed significantly ( $\chi^{2}$ test, $\mathrm{p}=0.037$ ).

\section{Shell morphology and reproductive anatomy}

Conch from high-density source sites had significantly thicker lips (ANOVA, p < 0.0005) and shorter shells (ANOVA, $p=0.003$ ) than conch from lowdensity source sites (Fig. 5); there were no significant differences in shell weight (ANOVA, $p=0.452$ ). The sexes did not differ significantly in shell characteristics (ANOVA, p = 0.260 [lip], 0.051 [length], 0.536 [weight]). The main reproductive structures were fully developed in all conch (males: verge, prostate gland, testes; females: ovary, uterus). The gonads of all males were orange, indicating that they were producing sperm (Reed 1995).

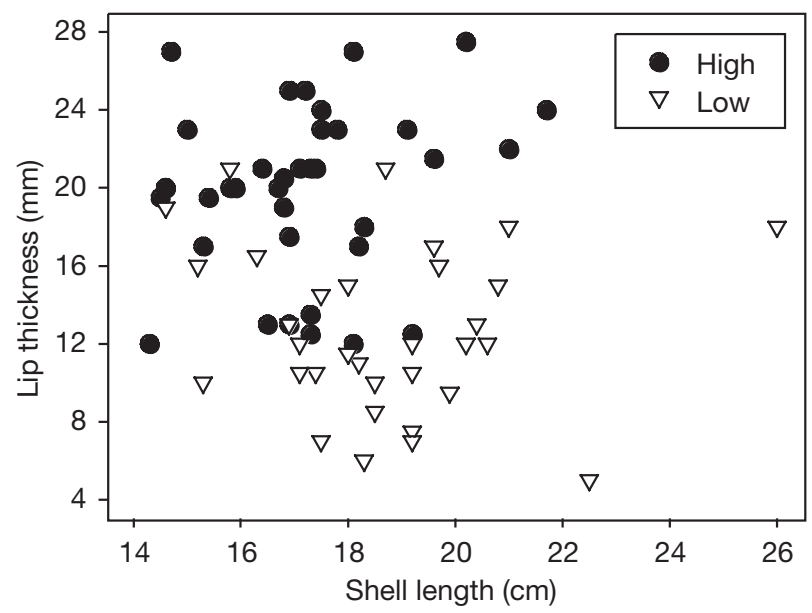

Fig. 5. Strombus gigas. Lip thickness (mm) and shell length (cm) for subsampled conch from high- and low-density sites. $\mathrm{N}=16$ for all sites except Rainbow, where $\mathrm{N}=14$

\section{Condition and resource allocation to reproduction}

The 2 variants of condition index (flesh weight:shell weight ratio, flesh weight:shell length ratio) gave similar results. There was a significant interaction effect between source site density and system (ANOVA, $\mathrm{p}=0.004, \mathrm{p}=0.01$ ) and source site density and sex (ANOVA, $\mathrm{p}=0.018, \mathrm{p}=0.007$ ). Flesh weight:shell length ratio also had a significant system $\times$ sex interaction (ANOVA, $\mathrm{p}=0.047$ ). When analysed within treatment combinations (SNK tests, $\alpha=0.05$ ), conch from 1 low-density site (Shark Rock) were in significantly better condition than conch from the other 3 sites according to both indices (Fig. 6). There were no significant differences in the ratio of gonad to somatic tissue by source density, site or sex, and no interaction effects (ANOVA, p $>0.05$ for all effects).

\section{Modelling}

In negative density-dependent models (Fig. 7: Null1 and Null2, Fig. 8: $\delta=1$ ) equilibrium population size declined in a log-linear fashion with increasing mortality from exploitation $(F)$. In contrast, equilibrium population size under either delayed reproduction (Fig. 7: Rep) or Allee effects (Fig. 8: $\delta=3$ and $\delta=5$ ) declined in a loglinear manner with increasing $F$ at low values of $F$, but then rapidly collapsed to extinction at moderate values of $F$. In the case of the Allee models (Fig. 8), increasing the value of $\delta$ did not affect the dynamics at low values of $F$, but it reduced the critical value at which the population collapsed to extinction. A strong Allee effect (Fig. 8: $\delta=5$ ) and heavy exploitation prior to the age of maturity (Fig. 7: Rep) had comparable, drastic effects on extinction probability under exploitation (Fig. 7: Rep).

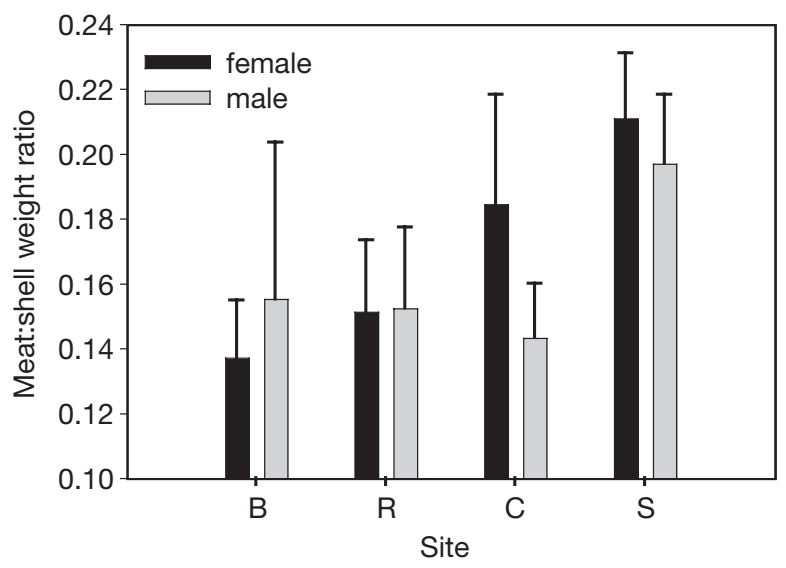

Fig. 6. Strombus gigas. Ratio of flesh wet weight (g) to shell weight (g) (condition index), by site and sex. Sites B and R are high-density sites; sites $\mathrm{C}$ and $\mathrm{S}$ are low-density sites 


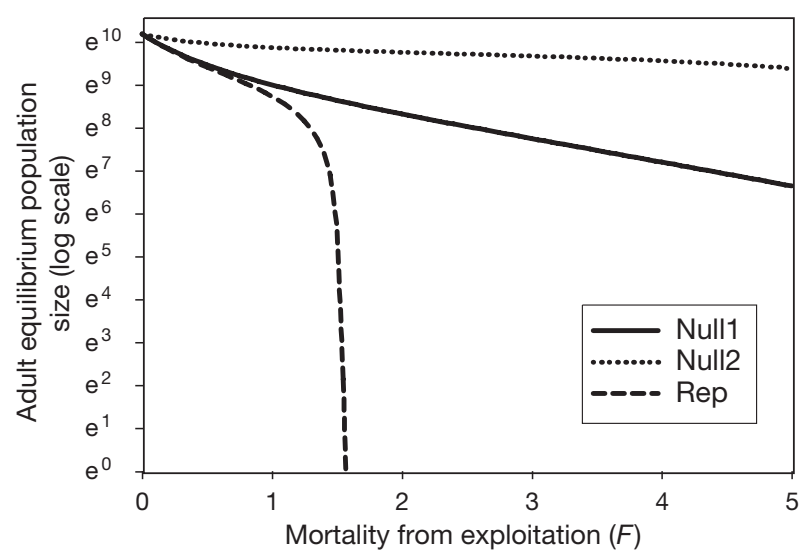

Fig. 7. Strombus gigas. Equilibrium adult population size versus exploitation mortality $(F)$ in model runs. Model Null1: all adults reproduce, all adults exploited; Null2: adult stages 1 and 2 do not reproduce and are not exploited; Rep: adult stages 1 and 2 do not reproduce but are exploited (delayed functional maturity model). The model is heuristic and only comparative values of population size and $F$ are meaningful

\section{DISCUSSION}

The major finding of this investigation is that the lack of reproductive activity in queen conch at low population density in seagrass beds could be due not just to an attenuation in encounter rate with potential mates (i.e. a classic Allee effect; Stoner \& Ray-Culp 2000), but also to other processes associated with low population density. A diminished encounter rate at low density may have a significant effect on reproduction in conch.

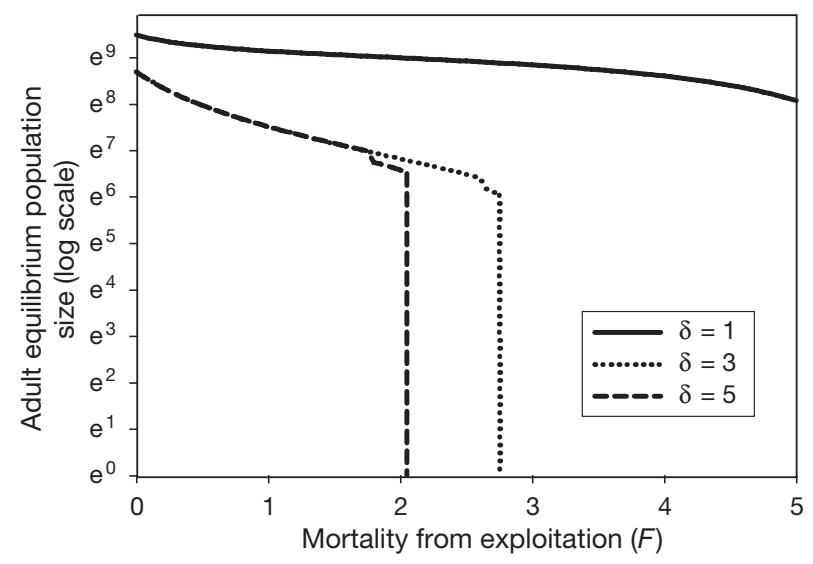

Fig. 8. Strombus gigas. Equilibrium adult population size versus exploitation mortality $(F)$ in Allee model runs. Allee models are similar to Model Null1 (see Fig. 7) but with an Allee effect in reproduction at low density. The value of $\delta$ indicates the strength of the Allee effect; $\delta=1$, no Allee effect; $\delta=3$, intermediate effect; $\delta=5$, strong effect (Stoner \& Ray-Culp 2000). The model is heuristic and only comparative values of population size and $F$ are meaningful
Although reproductive activity was never observed in the low-density sites in the field (Stoner \& Ray-Culp 2000, this study), there was some reproductive activity in conch from the low-density sites when translocated into the high density enclosures (Fig. 4). However, the significant differences in reproductive activity of conch held in various experimental treatments at high density indicate that there are additional significant processes acting on reproductive activity that can compound the Allee effect in encounter rates (Table 1). The decline in reproductive activity associated with low adult conch density apparently involves mechanisms related to age and reproductive behaviour, specifically delayed functional maturity in young adult queen conch. This finding regarding reproductive behaviour is consistent with independent analyses of histological condition of the gonads of queen conch at the same sites, whereby adult conch from the inshore, low-density site had undeveloped gonads and adult conch from offshore spawning areas at high density had fully developed gonads (R. Glazer pers. comm.).

It is critical to note that this study was carried out in different habitats than that of Stoner and Ray-Culp (2000), although in the same geographical location. They reported very little reproductive activity in conch populations in shallow seagrass beds, and concentrated on conch in deeper $(>10 \mathrm{~m})$ sand habitats. In surveys of sites appropriate for this experiment, highest densities of conch and rates of reproductive activity were in the high-density seagrass sites (Rainbow and Bock Cay) that we used in our investigation. It is therefore likely that the lowered reproductive activity at low-density offshore sites examined by Stoner and Ray-Culp (2000) was due not to delayed functional maturity, because the conch in those sites are substantially older than those in our inshore sites, but to an Allee effect in encounter rates of older, functionally mature conch.

The findings also indicate that an observed correlation between density or population size and some measure of fitness cannot be used exclusively as evidence for an Allee effect, which implies a causal relationship between population density and fitness (Courchamp et al. 1999, Stephens et al. 1999). Density and fitness may be related to a third causal factor, so that although mean fitness may decline in areas of low population density, it may nonetheless not be an Allee effect. A correlation between density and some measure of fitness has been used in many empirical studies of Allee effects to infer a causal relationship (e.g. Lamont et al. 1993, Shepherd \& Brown 1993, Clutton-Brock et al. 1999). In many cases, experimental tests of Allee effects are impractical (e.g. for protected species), but this study shows that the results of observational studies need to be interpreted with care. 
Our findings did not support the hypothesis that the reduction in queen conch reproductive activity in the shallow seagrass beds of our investigation was due exclusively to an Allee effect mediated by a reduced encounter rate at low population density. Various alternative hypotheses exist (Table 1). Two factors argue against the hypothesis that habitat quality in the low-density sites was poor (Table 1: $\mathrm{H}_{\mathrm{A} 4}$ ): (1) condition indices at low-density sites were comparable to highdensity sites or higher, and (2) high densities of juveniles periodically occurred at both of the low-density sites (Marshall 1992, Ray \& Stoner 1995, J. Gascoigne \& R. N. Lipcius pers. obs.).

Morphological differences between conch at the different sites allowed us to reject the hypothesis of free migration between high- and low-density sites (Table 1: $\mathrm{H}_{\mathrm{A} 2}$ ). The most likely explanation for the morphological differences between high- and low-density sites is that the adult conch at the low-density sites were younger (Stoner \& Schwarte 1994) and not functionally mature (Egan 1985). A difference in the ages of morphological and functional maturity has been observed in the queen conch (Egan 1985) and other gastropods (e.g. abalone; Shepherd \& Brown 1993), which tend to allocate an increasing proportion of resources to reproduction as they age (Yonge \& Thompson 1976), and in other invertebrates such as lobsters and crabs (Lipcius 1985). In general, late maturity will evolve in species with deterministic growth if reproduction is costly for future reproductive output or survival and if mortality is low (Roff 1992, Bulmer 1994). Conch reproduction may be costly, since sperm and eggs are energy rich (Reed 1995), and there is a cost to aggregation, at least in juveniles (Stoner \& Ray 1993).

Delayed functional maturity is an integral, evolved life-history component. Allee effects, in contrast, are either selectively neutral if conditions of low density rarely or never occur, or function as the cost component of a cost-benefit trade-off if they are a corollary of some trait that improves fitness at intermediate or high density. We therefore presumed that delayed functional maturity and Allee effects might have different effects on the population dynamics (McCarthy 1997). Simulated populations in the delayed maturity model and the Allee model fared worse than those in the null models - both the delayed functional maturity model (Model Rep in Fig. 7) and the Allee effect model (Models $\delta=3$ and $\delta=5$ in Fig. 8) affected population dynamics in a strikingly similar way, increasing vulnerability to exploitation and causing extinction at significantly lower values of mortality than the null models. Both exhibited threshold effects, with a rapid decline in the equilibrium population size to extinction above a critical value or small critical range of additional mortality.
From the perspective of queen conch conservation, our results are potentially disturbing since the basis of management in many areas, including the Bahamas, is a ban on the exploitation of conch until they have reached morphological maturity, as indicated by the presence of a 'well-formed' flaring lip. Our experimental findings indicate that young adult queen conch, which are legally exploited, may not be functionally mature even at lip thickness values up to $11 \mathrm{~mm}$ (Fig. 5). Hence, a large fraction of the population of queen conch may be subject to exploitation before reproducing, particularly young adult queen conch that are not functionally mature and that occur at low density in shallow seagrass habitats. This situation was modelled as the 'Rep' treatment in our simulations, with delayed reproduction and immediate exploitation of adults that do not reproduce. In this case, moderate levels of fishing mortality led to non-linear collapses in equilibrium population size, indicating that this species may be much more vulnerable to exploitation and population collapse than previously thought. In fact, population collapses have been common in heavily exploited queen conch populations (Berg \& Olsen 1989). Moreover, the likelihood of restoration success may be diminished substantially by a combination of Allee effects and delayed functional maturity. Thus, conservation efforts must be directed at those habitats that support young adults at low density, and not only to habitats where older functionally mature adults are at high density and not susceptible to Allee effects.

Acknowledgements. We are grateful to R. Woodman, K. S. Macdonald, M. Wong and C. Dahlgren for field assistance and the staff of the Caribbean Marine Research Center (CMRC) for logistical support. This work was funded by the National Science Foundation Biological Oceanography Program, CMRC (National Oceanographic and Atmospheric Administration-National Undersea Research Program), the Commonwealth of Virginia and a graduate fellowship to J.G. from the International Society for Reef Studies. Additional funding to J.G. came from the International Women's Fishing Association. This is contribution number 2600 from the Virginia Institute of Marine Science.

\section{LITERATURE CITED}

Allee WC (1931) Animal aggregations: a study in general sociology. University of Chicago Press, Chicago

Anonymous (1999) Queen Conch Stock Assessment and Management Workshop. Caribbean Fishery Management Council (CFMC), San Juan, Puerto Rico

Appeldoorn RS (1988a) Fishery pressure and reproductive potential in strombid conchs: is there a critical stock density for reproduction? Mem Soc Cienc Nat La Salle 48 S3:275-288

Appeldoorn RS (1988b) Ontogenetic changes in natural mortality rate of queen conch, Strombus gigas (Mollusca: Mesogastropoda). Bull Mar Sci 42:159-165

Baker MC, Tyler PA (2001) Fertilisation success in the com- 
mon gastropod Haliotis tuberculata. Mar Ecol Prog Ser 211:205-213

Berg CJ, Olsen DA (1989) Conservation and management of queen conch (Strombus gigas) fisheries in the Caribbean. In: Caddy JF (ed) Marine invertebrate fisheries: their assessment and management. Wiley \& Sons, New York, p 421-442

Bulmer M (1994) Theoretical evolutionary ecology. Sinauer Associates, Sunderland, MA

Caswell H (2001) Matrix population models: construction, analysis and interpretation. Sinauer Associates, Sunderland, MA

Clutton-Brock TH, Gaynor D, McIlrath GM, MacColl ADC and 5 others (1999) Predation, group size and mortality in a cooperative mongoose, Surivata suricatta. J Anim Ecol 68:672-683

Courchamp F, Clutton-Brock T, Grenfell B (1999) Inverse density dependence and the Allee effect. Trends Ecol Evol 14:405-410

Courchamp F, Clutton-Brock T, Grenfell B (2000) Multipack dynamics and the Allee effect in the African wild dog, Lycaon pictus. Anim Conserv 3:277-285

Delgado GA, Bartels CT, Glazer RA, Brown-Peterson NJ, McCarthy KJ (2004) Translocation as a strategy to rehabilitate the queen conch (Strombus gigas) population in the Florida Keys. US Fish Bull 102:278-288

Egan BD (1985) Aspects of the reproductive biology of Strombus gigas. MS thesis, University of British Columbia, Vancouver

Fowler CW, Baker JD (1991) A review of animal population dynamics at extremely reduced population levels. Rep Internat Whaling Comm 41:545-554

Glazer RA, Quintero I (1998) Observations on the sensitivity of queen conch to water quality: implications for coastal development. Proc Gulf Carib Fish Inst 50:78-93

Gotelli NJ (1998) A primer of ecology, 2nd edn. Sinauer Associates, Sunderland, MA

Groom MJ (1998) Allee effects limit population viability of an annual plant. Am Nat 151:487-496

Hackney EE, McGraw JB (2001) Experimental demonstration of an Allee effect in American ginseng. Conserv Biol 15:129-136

Kenward RE (1978) Hawks and doves: factors affecting success and selection in goshawk attacks on woodpigeons. J Anim Ecol 47:449-460

Kuussaari M, Saccheri I, Camara M, Hanski I (1998) Allee effect and population dynamics in the Glanville fritillary butterfly. Oikos 82:384-392

Lamont BB, Klinkhamer PGL, Witkowski ETF (1993) Population fragmentation may reduce fertility to zero in Banksia goodii-a demonstration of the Allee effect. Oecologia 94:446-450

Levitan DR, Sewell MA, Chia FS (1992) How distribution and abundance influence fertilization success in the sea urchin Strongylocentrus franciscanus. Ecology 73: $248-254$

Lipcius RN (1985) Size-dependent timing of reproduction and molting in spiny lobsters and other long-lived decapods. In: Wenner A (ed) Crustacean issues, Vol 3. Balkema, Rotterdam, p 129-148

Editorial responsibility: Kenneth Heck (Contributing Editor), Dauphin Island, Alabama, USA
Marshall LS (1992) Survival of juvenile queen conch Strombus gigas in natural habitats: impact of prey, predator and habitat features. PhD thesis, College of William and Mary, Williamsburg

McCarthy KJ, Bartels CT, Darcy MC, Delgado GA, Glazer RA (2002) Preliminary observation of reproductive failure in nearshore queen conch (Strombus gigas) in the Florida Keys. Proc Gulf Carib Fish Inst 53:674-680

McCarthy MA (1997) The Allee effect, finding mates and theoretical models. Ecol Model 103:99-102

Myers RA, Barrowman NJ, Hutchings JA, Rosenberg AA (1995) Population dynamics of exploited fish stocks at low population levels. Science 269:1106-1108

Randall JE (1964) Contributions to the biology of the queen conch, Strombus gigas. Bull Mar Sci 14:246-295

Ray M, Stoner AW (1995) Growth, survivorship and habitat choice in a newly settled seagrass gastropod, Strombus gigas. Mar Ecol Prog Ser 123:83-94

Reed SE (1995) Reproductive anatomy and biology of the genus Strombus in the Caribbean: I. Males. J Shellfish Res 14:325-330

Roff DA (1992) The evolution of life history. Chapman \& Hall, London

Shepherd SA, Brown LD (1993) What is an abalone stock? Implications for the role of refugia in conservation. Can J Fish Aquat Sci 50:2001-2009

Stephens PA, Sutherland WJ, Freckleton RP (1999) What is the Allee effect? Oikos 87:185-190

Stoner AW, Ray M (1993) Aggregation dynamics in juvenile queen conch (Strombus gigas): population structure, mortality, growth and migration. Mar Biol 116:571-582

Stoner AW, Ray-Culp M (2000) Evidence for Allee effects in an over-harvested marine gastropod: density-dependent mating and egg production. Mar Ecol Prog Ser 202:297-302

Stoner AW, Sandt VJ (1991) Experimental analysis of habitat quality for juvenile queen conch in seagrass meadows. US Fish Bull 89:693-700

Stoner AW, Sandt VJ (1992) Population structure, seasonal movements and feeding of queen conch, Strombus gigas, in deep-water habitats of the Bahamas. Bull Mar Sci 51: 287-300

Stoner AW, Schwarte KC (1994) Queen conch, Strombus gigas, reproductive stocks in the central Bahamas: distribution and probable sources. US Fish Bull 92:171-179

Stoner AW, Lipcius RN, Marshall LS Jr, Bardales AT (1988) Synchronous emergence and mass migration in juvenile queen conch. Mar Ecol Prog Ser 49:51-55

Stoner AW, Sandt VJ, Boidron-Metairon IF (1992) Seasonality in reproductive activity and larval abundance of queen conch Strombus gigas. US Fish Bull 90:161-170

Underwood AJ (1997) Experiments in ecology. Cambridge University Press, New York

Widen B (1993) Demographic and genetic effects on reproduction as related to population size in a rare, perennial herb, Senecio integrifolius (Asteraceae). Biol J Linn Soc 50:179-195

Yonge CM, Thompson TE (1976) Living marine molluscs. Collins, London

Zar JH (1999) Biostatistical analysis, 4th edn. Prentice Hall, Upper Saddle River, NJ

Submitted: August 9, 2002; Accepted: July 1, 2004

Proofs received from author(s): November 29, 2004 